\title{
Phase I Clinical Trial of Valacyclovir and Standard of Care Cyclophosphamide in Children With Endemic Burkitt Lymphoma in Malawi
}

\author{
Dan Olson ${ }^{1,2}$, Margaret L. Gulley ${ }^{3,4}$, Weihua Tang ${ }^{3,4}$, Clifford Wokocha ${ }^{5}$, Oren Mechanic ${ }^{6}$, \\ Mina Hosseinipour ${ }^{1,7}$, Stuart H. Gold ${ }^{4,8}$, Nelson Nguluwe ${ }^{1}$, Charles Mwansambo ${ }^{5}$, and \\ Carol Shores ${ }^{4,9}$ \\ ${ }^{1}$ University of North Carolina Project, Lilongwe, Malawi \\ ${ }^{2}$ Fogarty International Center, National Institutes of Health, Bethesda, MD \\ ${ }^{3}$ Department of Pathology and Laboratory Medicine, University of North Carolina, Chapel Hill, NC \\ ${ }^{4}$ UNC Lineberger Comprehensive Cancer Center, Chapel Hill, NC \\ ${ }^{5}$ Department of Pediatrics, Kamuzu Central Hospital, Lilongwe, Malawi \\ ${ }^{6}$ University of North Carolina, School of Medicine, Chapel Hill, NC \\ ${ }^{7}$ Department of Medicine, Division of Infectious Disease, University of North Carolina, Chapel Hill, \\ NC \\ ${ }^{8}$ Department of Pediatrics, University of North Carolina, School of Medicine, Chapel Hill, NC \\ ${ }^{9}$ Department of Otolaryngology/Head and Neck Surgery, University of North Carolina, Chapel Hill, \\ $\mathrm{NC}$
}

\begin{abstract}
Treatment options for Epstein-Barr virus (EBV)-associated Burkitt lymphoma in Africa are limited because of chemotherapy-associated toxicity. Since other EBV-associated diseases respond to antiviral agents, we investigated adding an antiviral agent, valacyclovir, to the current chemotherapy regimen in Malawi. In this phase I safety study, we showed that cyclophosphamide combined with valacyclovir was safe. Phase II efficacy trials should now be undertaken.
\end{abstract}

\begin{abstract}
Background-Nucleoside analogues, including acyclovir, ganciclovir, and their precursors, have shown some efficacy against several Epstein-Barr virus (EBV)-associated diseases, including active EBV infection and posttransplantation lymphoproliferative disorder (PTLD). They have also been proposed as a possible treatment for EBV-associated malignancies, including endemic Burkitt lymphoma. The safety of nucleoside analogues in combination with chemotherapy in the developing world has not been studied and is necessary before any large scale efficacy trials are conducted.
\end{abstract}

(C) 2012 Elsevier Inc. All rights reserved.

Address for correspondence: Daniel Olson, MD, Department of Infectious Diseases, University of Colorado - Denver, 13123 E 16th Ave, Box 055, Aurora, CO 80045 Fax: (720) 777-7295; daniel.olson@ childrenscolorado.org.

Publisher's Disclaimer: This is a PDF file of an unedited manuscript that has been accepted for publication. As a service to our customers we are providing this early version of the manuscript. The manuscript will undergo copyediting, typesetting, and review of the resulting proof before it is published in its final citable form. Please note that during the production process errors may be discovered which could affect the content, and all legal disclaimers that apply to the journal pertain.

Disclosure

The authors have stated that they have no conflicts of interest. 
Patients and Methods-Children 3-15 years old meeting inclusion criteria were assigned to a $3+3$ dose escalation trial of combination valacyclovir ( 15 and $30 \mathrm{mg} / \mathrm{kg}, 3$ times daily for 40 days) and cyclophosphamide (CPM) $(40 \mathrm{mg} / \mathrm{kg}$ day $1,60 \mathrm{mg} / \mathrm{kg}$ on days 8,18 , and 28$)$ or CPM monotherapy. Subjects were monitored for clinical and laboratory toxicity and had EBV levels measured regularly. Dose-limiting toxicity (DLT) was our primary outcome.

Results-We found that the combination of valacyclovir and CPM was safe and did not lead to any DLT compared with CPM monotherapy. The most common side effects were vomiting, abdominal pain, and tumor site pain, which were similar in both arms. Patients with measurable serum EBV showed decreased loads over their treatment course.

Conclusions-We recommend a phase II valacyclovir dose of $30 \mathrm{mg} / \mathrm{kg} 3$ times daily for 40 days. We also observed that 6 of our 12 patients with presumed Burkitt lymphoma had measurable EBV viral loads that decreased over the course of their treatment, suggesting that phase II studies should investigate this correlation further. This study paves the way for a phase II efficacy trial of combined valacyclovir and CPM in the treatment of endemic Burkitt lymphoma.

\section{Introduction}

Epstein-Barr virus (EBV) is a human herpesvirus that infects $90 \%$ of adults globally. EBV can immortalize human B lymphocytes in cell culture and has been implicated in human lymphomagenesis. ${ }^{1}$ Lymphoma subtypes having a strong association with EBV include Burkitt lymphoma (BL), Hodgkin lymphoma (HL), B-cell lymphoproliferative disease in immunosuppressed patients, and nasal NK-T-cell lymphoma. In areas endemic for BL, such as Malawi and much of sub-Saharan Africa, virtually all tumors carry the virus, whereas EBV is present in $15 \%$ to $20 \%$ of sporadic BL tumors occurring in high-income countries. ${ }^{2-4}$ EBV infection is operative surgically in $90 \%$ of patients with posttransplantation lymphoproliferative disease (PTLD), which occurs in up to 5\% of organ transplant recipients. Decreasing EBV-specific cytotoxic T lymphocytes and increasing EBV viral load are strongly associated with PTLD development. ${ }^{5-7}$ EBV positivity is more frequent in patients with HIV-associated non-Hodgkin lymphoma (NHL) than in NHL in immunocompetent individuals, which is also likely a consequence of chronically impaired cellular immunity. ${ }^{8}$ As effective antiretroviral therapy has led to marked reductions in HIVassociated infectious complications, NHL has emerged as a principal cause of morbidity and mortality among persons living with HIV in high-income countries. ${ }^{9-11}$ In patients with HIV-associated NHL, EBV positivity has been demonstrated in $30 \%$ to $40 \%$ of HIVassociated BL, $70 \%$ to $80 \%$ of HIV-associated diffuse large B-cell and plasmablastic lymphoma, and virtually $100 \%$ of HIV-associated primary central nervous system (CNS) lymphoma. ${ }^{12-14}$

It has been speculated that the addition of antiviral agents to chemotherapeutic agents in EBV-related cancers would improve disease-free survival. ${ }^{15}$ Nucleoside analogue antiviral agents such as valacyclovir are activated by EBV thymidine kinase $(B X L F 1)$ or serine/ threonine protein kinase/phosphotransferase (BGLF4), which are expressed only during the lytic phase of EBV replication. In most EBV-related cancers, the virus exists in a latent form and therefore does not express these kinases. However cells with latent EBV infection can be induced to lytic infection with chemotherapy or radiation in vitro and in animal models. ${ }^{16-20}$ Our proof of principle study of Malawian children with endemic BL found that cyclophosphamide (CPM) induces EBV lytic-phase replication within 24 hours of initial treatment. $^{21}$

Nucleoside analogues have shown efficacy in managing active EBV infection, ${ }^{22}$ leading to decreased oropharyngeal EBV titers among patients with infectious mononucleosis. ${ }^{23}$ Antiviral therapy directed against EBV has been principally studied in the context of PTLD 
and is generally ineffective (likely because the cells are latently infected), although there are anecdotal reports of clinical response. ${ }^{24}$ More recently, a novel treatment strategy using ganciclovir in combination with arginine butyrate - an amino acid derivative that induces EBV thymidine kinase transcription and renders latently infected immortalized B lymphocytes susceptible to ganciclovir-has shown some promise. ${ }^{25}$ As antiviral and immunologic therapies directed against EBV continue to show promise in the context of PTLD, these strategies may demonstrate applicability to other EBV-related lymphoproliferative disorders.

Endemic BL in sub-Saharan Africa occurs in tropical malaria-prevalent areas. The median age of onset is 8 years, and $60 \%$ to $70 \%$ of patients present with rapid tumor growth in the mandible and/or maxilla, although abdominal, CNS, and other sites can also be involved. ${ }^{26}$ In high-income countries, treatment typically includes a combination of CPM, vincristine, methotrexate, and additional agents, leading to survival rates $>90 \% .{ }^{27}$ Without adequate resources for supportive care, similar multidrug regimens used in Malawi had only 33\% 1year disease-free survival and unacceptably high levels of toxicity, with 14/42 (33\%) cases of mortality occurring during or directly after treatment ( 3 cases were attributed to disease progression). ${ }^{28}$ In addition, chemotherapy agents are in limited supply. As a result, treatment for BL at Kamuzu Central Hospital in Lilongwe, Malawi is generally CPM monotherapy, given at $40 \mathrm{mg} / \mathrm{kg}$ once, followed by $60 \mathrm{mg} / \mathrm{kg}$ every 10 days for 3 more doses. Long-term survival rates with this regimen are $48 \%$ (median follow up, 454 days). ${ }^{4}$

Although ganciclovir has thus far shown slightly greater efficacy against EBV-associated disease such as PTLD ${ }^{29}$ acyclovir has the advantages of being less toxic, less expensive, and easier to dose, ${ }^{30-32}$ all of which are important factors in a resource-limited setting with a proven history of inadequate supportive care. ${ }^{28}$ Valacyclovir is inexpensive and is approved for use in the United States in children with herpes labialis ( $>12$ years of age at $2 \mathrm{~g}$ every 12 hours for 1 day) and chickenpox (age $>2$ years, $20 \mathrm{mg} / \mathrm{kg} 3$ times daily for 5 days). Pharmacokinetic data in a study of children with EBV infection suggested that a valacyclovir dose of $20 \mathrm{mg} / \mathrm{kg}$ is effective. ${ }^{33}$ The recommended prophylactic dose in immunocompromised children is $30 \mathrm{mg} / \mathrm{kg} 3$ times daily. ${ }^{34}$ Although valacyclovir monotherapy has thus far proved safe, the safety of combined valacyclovir with CPM or other chemotherapeutic agents in children with BL in sub-Saharan Africa has not been assessed. These children are universally infected with malaria and are frequently malnourished. Therefore phase I safety data are necessary to assess this combination and dosing regimen before a phase II trial can be initiated.

The primary objectives of our study were to assess the toxicity of combined valacyclovir/ CPM and to determine a maximum tolerated dose (MTD) or a recommended phase II dose for this regimen. Endemic BL provides a homogeneous population of EBV-associated cancers to test the hypothesis that chemotherapy-induced lytic EBV infection will render EBV-associated cancer cells susceptible to increased cell death by antiviral nucleoside analogues.

\section{Patients and Methods}

\section{Patients}

Children aged 3 to 15 years with expanding maxillary or mandibular masses, no previous history of cancer treatment, and a Lansky performance score ${ }^{35}$ of 50 or greater were eligible for the study. Although pathologic specimens were sent for histologic confirmation of BL, treatment was initiated presumptively per standard of care, as pathologic confirmation can take 6 to 8 weeks. Minimum laboratory requirements for study inclusion were a hemoglobin level of $7 \mathrm{~g} / \mathrm{dL}$ (after $10 \mathrm{~mL} / \mathrm{kg}$ of whole blood transfusion if needed), white blood cell count 
of 2000 cells $/ \mu \mathrm{L}$, absolute neutrophil count (ANC) of 1000 cells $/ \mu \mathrm{L}$, and platelet count of 50,000 cells $/ \mu \mathrm{L}$. The maximum creatinine level allowed was $2.0 \mathrm{mg} / \mathrm{dL}$. Subjects were excluded for CNS symptoms (facial weakness, nonreactive pupil, marked visual changes), known intolerance to study medications, or if they were receiving other investigational drugs.

The study was approved by the University of North Carolina (UNC) Internal Review Board (Study No. 10-0962) and the Malawi National Health Sciences Research Committee (protocol 735). All guardians provided written informed consent before enrollment in the study and age-appropriate children were asked to sign an assent.

\section{Study Design}

In this phase I open-label $3+3$ dose-escalation study, we evaluated the safety and tolerability of increasing doses of valacyclovir in combination with standard-dose CPM in the treatment of BL in Malawi. Patients were enrolled at $15 \mathrm{mg} / \mathrm{kg}$ valacyclovir 3 times daily for 40 days (day-2 to 38, level 1) and $30 \mathrm{mg} / \mathrm{kg} 3$ times daily for 40 days (level 2); 15 $\mathrm{mg} / \mathrm{kg} 3$ times daily for 12 days (level -1 ) was planned but was not used. All patients received CPM $40 \mathrm{mg} / \mathrm{kg}$ intravenously on day 1 and then $60 \mathrm{mg} / \mathrm{kg}$ on days 8,18 , and 28 , as is standard of care at Kamuzu Central Hospital, Lilongwe, Malawi. Study nurses provided all doses of CPM and all doses of valacyclovir except in rare circumstances, ensuring compliance. CPM dosing was delayed for hemoglobin levels $<7 \mathrm{~g} / \mathrm{dL}$ (after $10 \mathrm{~mL} / \mathrm{kg}$ of whole blood transfusion if needed), white blood cell count $<2000$ cells $/ \mu \mathrm{L}$, ANC $<1000$ cells $/ \mu \mathrm{L}$, platelet count $<50,000$ cells $/ \mu \mathrm{L}$, and creatinine levels $<2.0 \mathrm{mg} / \mathrm{dL}$, until those values normalized. Dose-limiting toxicity (DLT) for combination valacyclovir and CPM was defined as grade 3 or greater nonhematologic toxicity that was at least possibly attributable to protocol therapy (except grade 3 nausea and vomiting that could be controlled with antiemetic therapy and grade 3 infections), grade 4 hematologic toxicity lasting more than 3 weeks, and grade 4 infections. ${ }^{36}$ Febrile neutropenia is common with CPM therapy and has not been reported with valacyclovir. Therefore febrile neutropenia was not counted as a DLT for this trial. Many patients receiving CPM are treated with intravenous antibiotics, the definition of grade 3 infection, so this also was not counted as a DLT.

The dose-escalation plan was as follows: a 3-patient cohort was enrolled at dosage level 1, $(15 \mathrm{mg} / \mathrm{kg} / \mathrm{dose} 3$ times daily of valacyclovir from days -2 to 38$)$ and was observed through days 35 to 38 (7-10 days after the fourth dose of CPM). If no DLT was observed after all 3 subjects reached day 35 , the dosing was escalated to $30 \mathrm{mg} / \mathrm{kg} / \mathrm{dose} 3$ times daily of valacyclovir from days -2 to 38 (dose level 2) in another 3-patient cohort. If 1 DLT was observed at dose level 1,3 more subjects would enroll at dose level 1 and would be observed through day 38 (10 days after the last dose of CPM). If 1 of 6 subjects had DLTs at dose level 1, the study would escalate to dose level 2. If 2 or more DLTs were observed in 6 subjects at dose level 1, 3 subjects would enroll at dose level $-1(15 \mathrm{mg} / \mathrm{kg} / \mathrm{dose}$ valacyclovir 3 times daily on days -2 to 10). If there were no DLTs in these 3 subjects, dose level -1 would be considered the MTD. If 1 DLT occurred in the first 3 subjects enrolled at dose level $-1,3$ more subjects would be enrolled. If $0 / 3$ or one-sixth of the subjects receiving dose level -1 had a DLT, this would be considered the MTD. If 2 or more DLTs occurred in 6 subjects at dose level -1 , the combination of valacyclovir and CPM would be reviewed by both the Malawi and the UNC data safety monitoring committees to determine if it was too toxic to consider a phase II trial.

If the study escalated to dose level 2, 3 subjects would be enrolled at this level and observed. If no DLT was observed, $30 \mathrm{mg} / \mathrm{kg} /$ dose given 3 times daily would be considered the recommended phase II dose, and a phase II study would be planned. If 1 DLT was observed in the cohort of 3 subjects, 3 more subjects would be enrolled at dose level 2. If 1 or fewer 
DLTs were observed in 6 subjects at dose level $2,30 \mathrm{mg} / \mathrm{kg} / \mathrm{dose}$ given 3 times daily would be considered the MTD. If 2 or more DLTs were observed at dose level 2, the MTD would be exceeded, and dose level 1 would be considered the MTD.

Throughout the dose escalation, an equal number of control patients were enrolled in the CPM arm. Toxicities were recorded for comparison in the same manner as the experimental (combination CPM/valacyclovir) arm.

\section{Assessments}

Baseline data were collected before initiation of chemotherapy and included a complete history, physical examination, tumor measurements, abdominal ultrasonogram, fine-needle aspiration of tumor for histopathologic examination, and plasma EBV viral load measurement. There is no scanning radiography at Kamuzu Central Hospital, so tumor response was determined by clinically measuring tumor size with a tape measure in horizontal, vertical, and longest dimensions. Plasma EBV levels were determined between doses 3 and 4 of valacyclovir, within 6 hours of the first CPM dose, <48 hours before each subsequent CPM dose, and 7 to 14 days after the final scheduled dose of CPM. A complete history, physical examination including tumor measurements, and laboratory tests (hemoglobin, hematocrit, white blood cell count with differential, platelets, creatinine, and lactate dehydrogenase determinations) were performed $<48$ hours before each CPM dose, 7 to 14 days after the final scheduled dose of CPM, and as needed according to the Burkitt ward clinician. The abdominal ultrasonogram was not repeated unless there was a recurrence of disease.

\section{Pathologic Examination}

Kamuzu Central Hospital clinicians performed fine-needle aspiration by routine methods. Samples were sent to the Imperial College London in London for analysis, and results were not available before patients initiated treatment or during the trial.

\section{EBV Viral Load}

Blood was collected in a 5-mL ethylenediaminetetraacetic acid tube, and plasma separation was performed within 4 hours. In the event of delay, the specimen was held at room temperature for no more than 24 hours. Tubes were rotated gently 2 or 3 times and then centrifuged at $500 \mathrm{~g}$ for 10 minutes. One-milliliter aliquots of plasma were removed and put into $1.5-\mathrm{mL}$ screw-top tubes and transferred to $-80^{\circ} \mathrm{C}$ for storage and shipping on dry ice from Malawi to UNC for testing.

Total nucleic acid was extracted from $200 \mu \mathrm{L}$ of plasma using the High Pure Viral Nucleic Acid Kit (Roche Diagnostics, Indianapolis, IN). Before extraction, $1 \mu \mathrm{L}$ of TaqMan exogenous internal positive control (Exo IPC [Applied Biosystems, Foster City, CA]) was spiked directly into $200 \mu \mathrm{L}$ of plasma to serve as an indicator of adequate DNA extraction and amplification, and all specimens in this study were deemed adequate on interpretation of the results. The final elution volume was $50 \mu \mathrm{L}$, and $5 \mu \mathrm{L}$ was used for each polymerase chain reaction (PCR). EBV BamH1W region PCR was run on ABI 7500 Real Time PCR System (Applied Biosystems, Carlsbad, CA) in duplicate for each sample. EBV viral load was calculated in EBV genome copies per milliliter plasma. Undetectable EBV DNA, reported as a value of 1 for purposes of data analysis, indicates that results were smaller than the limit of detection ( 250 copies per $\mathrm{mL}$ ). Standards, primer sequences, and thermocycler conditions were as previously described..$^{37}$ 


\section{Statistical Analysis}

Sample size of the experimental arm was determined per $3+3$ study design with an equal number of controls. Summary statistics were calculated for continuous and discrete variables.

\section{Results}

\section{Patients}

Between January and June 2011, 13 patients were enrolled in the study, 3 at valacyclovir dosage level 1 (15 mg/kg 3 times daily), 4 at dosage level $2(30 \mathrm{mg} / \mathrm{kg} 3$ times daily), and 6 as controls. One patient at dosage level 2 absconded after her second dose of CPM for social reasons after near resolution of the tumor and was replaced.

Of the subjects completing treatment and the 1 who absconded, ages ranged from 3 to 15 years and there were 5 boys and 8 girls (Table 1). Children in the control group and valacyclovir dosage level 1 group were stunted, with median height $z$ scores of -3.28 and -1.99 , respectively. Reported duration of facial swelling on presentation ranged from 7 days to 3 months. Abdominal masses confirmed by ultrasonography were found in 3 control subjects, 2 subjects receiving valacyclovir dosage level 1, and all 3 subjects on valacyclovir dosage level 2 (58\% of all patients). All subjects had a Lansky performance score of 100.

Only 2 patients had biopsy-confirmed BL, including the patient who absconded, with the remaining subjects having fine-needle aspirations with inadequate samples.

\section{Safety}

No DLTs or grade 3 or 4 adverse events attributable to the combination of valacyclovir and CPM were observed. One patient experienced grade 3 anemia (hemoglobin level of $7.5 \mathrm{~g} /$ $\mathrm{dL}$ ) on study day 6 . The patient had confirmed malaria based on a positive malaria parasite smear with symptomatic recovery after 3 days of treatment, so this grade 3 toxicity was attributed to malaria. Nearly all patients experienced grade 1 or 2 vomiting in the control $\operatorname{arm}(5 / 6$ patients), in the valacyclovir dosage level 1 ( $3 / 3$ patients) arm, and in the dosage level 2 (2/3 patients) arm (Table 2). All subjects had some degree of anemia. Estimated creatinine clearance was similar between control $(114.1 \mathrm{~mL} / \mathrm{min})$ and treatment $(133.0 \mathrm{~mL} /$ $\min )$ groups.

Essentially all patients experienced neutropenia, and 6 of 6 control and 3 of 6 experimental arm patients experienced CPM treatment delays for neutropenia of 2 to 20 days. In eightninths of these cases, the neutropenia occurred on day 16, between the second and third doses of CPM. This is expected for patients treated with CPM and were not counted as DLTs for the combination of valacyclovir and CPM.

No DLT attributable to the addition of $30 \mathrm{mg} / \mathrm{kg} /$ dose 3 times daily valacyclovir on days -2 to 38 to standard of care CPM was identified.

\section{Efficacy}

Of the 12 patients who completed therapy in all arms, 10 had a complete or nearly complete response to treatment as measured by a change in tumor size at their day 35 to day 38 follow-up evaluation. For those patients with a partial response, we were unable to determine whether a remaining mass was residual tumor or scar. One control patient and 1 patient receiving combined valacyclovir and CPM in the $30 \mathrm{mg} / \mathrm{kg}$ dose had progressive disease at the end of treatment. 


\section{EBV Viral Load}

Six of the 12 patients who finished treatment had a baseline detectable EBV viral load in plasma. The 2 patients with progressive disease never had detectable circulating EBV DNA. In all patients with an initial detectable EBV load, the viral load fell dramatically on treatment with CPM, to nearly undetectable levels before the fourth dose (Figure 1). A transient rise in plasma EBV viral load was seen in nearly all patients at various time points during sequential monitoring of response to therapy, although by the end of therapy most patients had achieved a 100- to 1000-fold reduction in EBV load. In this small study, there was no discernible difference in serial viral loads between the 4 patients treated with CPM and the 2 patients who received both CPM and valacyclovir.

\section{Discussion}

In this $3+3$ phase I dose escalation study of endemic BL, the combination of valacyclovir and CPM was safe in the study population and did not lead to any DLTs or serious adverse events. The valacyclovir recommended phase II dose is $30 \mathrm{mg} / \mathrm{kg} 3$ times daily for 40 days with a CPM dose of $40 \mathrm{mg} / \mathrm{kg}$ on day 1 , followed by $60 \mathrm{mg} / \mathrm{kg}$ on days 8,18 , and 28 .

The most commonly reported adverse events in patients treated with and without valacyclovir were vomiting, abdominal pain, and local pain at the tumor site, none of which were grade 3 or greater. Adverse events occurred with equal frequency in both study arms, and most symptoms reported are commonly associated with cyclophosphamide, ${ }^{38}$ suggesting that the addition of valacyclovir had a minimal impact on adverse events in this cohort.

Although anemia was frequent in both study arms, the average hemoglobin concentration of a healthy population of children in Malawi is $9.9 \mathrm{~g} / \mathrm{dL}$, and anemia secondary to malaria is common. ${ }^{39}$ Malaria, with concurrent anemia, developed in 2 patients in the study during treatment.

Six patients had a high plasma EBV viral load on diagnosis, and in all cases the viral load remained elevated after the first dose of CPM but then decreased to nearly undetectable levels over time. For the 2 patients receiving valacyclovir, there did not appear to be a significant change in viral load during the 2-day period between when valacyclovir was initiated and just before CPM was initiated, suggesting that the nucleoside analogue alone has little impact on circulating EBV DNA levels. However CPM treatment clearly had an effect on viral load. Six hours after the first dose of CPM, 2 of 5 evaluable patients had increases in viral load. Our observation of transient elevation of viral load is consistent with the findings in our proof of principle study, which also demonstrated an initial rise in EBV viral load in about half of patients with BL treated with CPM. ${ }^{21} \mathrm{~A}$ transient rise in EBV viral load has also been reported in EBV-infected nasopharyngeal carcinoma in which researchers found that although EBV viral load becomes undetectable within 2 hours of surgical resection, ${ }^{40}$ radiotherapy may lead to a transient increased EBV viral load that is thought to be associated with tumor lysis. ${ }^{41}$ Six patients had undetectable EBV at diagnosis. It is possible that in this small sample, the EBV-negative subjects had tumors other than EBV-infected BL, although this finding differs from our proof of concept study, which showed that 25/33 children (76\%) with expanding solid maxillary or mandibular masses were confirmed as having EBV-positive BL. ${ }^{21}$ The exact role of EBV in cellular transformation and tumorigenesis is still poorly understood. ${ }^{42}$ Although data are significantly limited, loss of EBV positivity has been reported in relapse among patients with HL, suggesting that EBV infection may not be necessary once transformation has occurred. ${ }^{43}$ Improved biopsy procedures and a larger sample size in a phase II trial would provide a better understanding of this discrepancy. 
In nasopharyngeal carcinoma, EBV load may serve as a marker of disease progression. The continued presence of circulating EBV 6 to 8 weeks after initiation of treatment was predictive of residual disease, whereas undetectable EBV was associated with stable remission. ${ }^{41,44,45}$ Serial testing was also shown to predict relapse before it became symptomatic. ${ }^{45-47}$ To our knowledge, EBV load as a marker of disease burden has not been established in EBV-related BL. For those patients in our study with a partial tumor response, the histopathologic type of the residual mass was unknown, and we followed patients up to 38 days only, not a full year. However in our experience, many patients have a clinical partial response as the tumor is replaced by scar, but they maintain a long disease-free interval. Given these clinical characteristics, future studies should investigate the role of circulating EBV loads and follow them for a longer period to learn the kinetics of EBV viral load and its ability to predict tumor remission vs. relapse.

The lack of adequate biopsy specimens was unexpected in the study but does not affect the conclusion that the combination of valacyclovir and CPM is safe in this patient population. Patients presenting with suspected BL from January 2011 to August 2011 who were not enrolled in the study also had an unexpectedly high rate of inadequate samples: $31 \%$ were inadequate, $33 \%$ were blood only, and only $31 \%$ were BL. The cause for an increased rate of assay failure compared with previous years is unclear because there was no obvious change in the method of collection, preparation, or shipment of these samples, which have been analyzed in this fashion for many years. In our previous proof of principle study, specimens from fine-needle aspiration performed by the same Kamuzu Central Hospital clinician were sent to the UNC and 25/33 children with expanding solid maxillary or mandibular masses were confirmed as having EBV-positive BL as determined by UNC pathologists. ${ }^{21}$ Three children had blood only in the specimen (likely geographic miss of lymphoma), 3 children had other pathologic processes ( 1 each diffuse large cell lymphoma, granuloma, and reactive node), and 2 specimens were inconclusive. After the last patient was enrolled in the current study in July 2011, a pathology laboratory was opened at Kamuzu Central Hospital in Malawi in collaboration with the UNC Project. Fine needle aspiration specimens are now processed promptly and interpreted within 2 weeks. This should facilitate diagnosis and timely tailored action by clinicians based on clinical findings combined with histopathologic classification of the lesion. Another limitation of our study is that subjects in the control arm had lower height-for-age $z$ scores than did the subjects in the experimental arm. Malnutrition and height stunting are common among children with cancer in the developing world, ${ }^{48}$ especially in Malawi, ${ }^{49}$ and have been shown to correlate with worse outcomes, including overall decreased response to treatment ${ }^{50}$ as well as increased episodes of profound neutropenia in patients with BL. ${ }^{51}$

Our data show that the addition of valacyclovir to standard of care CPM treatment for endemic BL did not increase the risk of grade 3 or 4 adverse events. Subjects continued to show a range of responses to treatment, but this phase I trial was not designed or powered to examine efficacy. A phase II trial is planned to investigate efficacy and to further define the side effect profile of combination valacyclovir and CPM in the treatment of endemic BL. Although BL is relatively rare in developed countries, the study of endemic BL provides a homogeneous population of EBV-associated cancer to test the hypothesis that chemotherapy-induced lytic EBV infection will render EBV-associated cancer cells susceptible to increased cell death by an antiviral nucleoside analogue.

\section{Acknowledgments}

We would like to thank our study nurses, Mary Chasela and Mary Mtunda, and the staff at UNC Project for their contributions, in particular the pharmacy and laboratory departments. 
This work was supported by the National Institutes of Health Office of the director, Fogarty International Center, Office of AIDS Research, National Cancer Centre, National Eye Institute, National Heart, Blood and Lung Institute, National Institute of Dental and Craniofacial Research, National Institute on Drug Abuse, National Institute of Mental Health, National Institute of Allergy and Infectious Diseases, and National Institutes of Health Office of Women's Health and Research through the Fogarty International Clinical Research Scholars and Fellows Program at Vanderbilt University (R24 TW007988), and the American Relief and Recovery Act.

\section{References}

1. Thorley-Lawson DA, Gross A. Persistence of the Epstein-Barr virus and the origins of associated lymphomas. N Engl J Med. 2004; 350:1328-1337. [PubMed: 15044644]

2. Gulley ML, Tang W. Laboratory assays for Epstein-Barr virus-related disease. J Mol Diagn. 2008; 10:279-292. [PubMed: 18556771]

3. de-Thé G. Epstein-Barr virus and Burkitt's lymphoma worldwide: the causal relationship revisited. IARC Sci Publ. 1985; 60:165-176. [PubMed: 2998987]

4. Kazembe P, Hesseling PB, Griffin BE, et al. Long term survival of children with Burkitt lymphoma in Malawi after cyclophosphamide monotherapy. Med Pediatr Oncol. 2003; 40:23-25. [PubMed: 12426682]

5. Davis JE, Sherritt MA, Bharadwaj M, et al. Determining virological, serological and immunological parameters of EBV infection in the development of PTLD. Int Immunol. 2004; 16:983-989. [PubMed: 15159377]

6. Green M. Management of Epstein-Barr virus-induced post-transplant lymphoproliferative disease in recipients of solid organ transplantation. Am J Transplant. 2001; 1:103-108. [PubMed: 12099356]

7. Opelz G, Döhler B. Lymphomas after solid organ transplantation: a collaborative transplant study report. Am J Transplant. 2004; 4:222-230. [PubMed: 14974943]

8. Kersten MJ, Klein MR, Holwerda AM, et al. Epstein-Barr virus-specific cytotoxic T cell responses in HIV-1 infection: different kinetics in patients progressing to opportunistic infection or nonHodgkin's lymphoma. J Clin Invest. 1997; 99:1525-1533. [PubMed: 9119996]

9. Antiretroviral Therapy Cohort Collaboration. Causes of death in HIV-1-infected patients treated with antiretroviral therapy, 1996-2006: collaborative analysis of 13 HIV cohort studies. Clin Infect Dis. 2010; 50:1387-1396. [PubMed: 20380565]

10. Achenbach CJ, Cole SR, Kitahata MM, et al. Mortality after cancer diagnosis in HIV-infected individuals treated with antiretroviral therapy. AIDS. 2011; 25:691-700. [PubMed: 21160411]

11. Simard EP, Engels EA. Cancer as a cause of death among people with AIDS in the United States. Clin Infect Dis. 2010; 51:957-962. [PubMed: 20825305]

12. Carbone A, Gloghini A. AIDS-related lymphomas: from pathogenesis to pathology. Br J Haematol. 2005; 130:662-670. [PubMed: 16115121]

13. Castillo J, Pantanowitz L, Dezube BJ. HIV-associated plasmablastic lymphoma: lessons learned from 112 published cases. Am J Hematol. 2008; 83:804-809. [PubMed: 18756521]

14. MacMahon EM, Glass JD, Hayward SD, et al. Epstein-Barr virus in AIDS-related primary central nervous system lymphoma. Lancet. 1991; 338:969-973. [PubMed: 1681341]

15. Israel BF, Kenney SC. Virally targeted therapies for EBV-associated malignancies. Oncogene. 2003; 22:5122-5130. [PubMed: 12910249]

16. Feng WH, Hong G, Delecluse HJ, et al. Lytic induction therapy for Epstein-Barr virus-positive Bcell lymphomas. J Virol. 2004; 78:1893-1902. [PubMed: 14747554]

17. Westphal EM, Blackstock W, Feng W, et al. Activation of lytic Epstein-Barr virus (EBV) infection by radiation and sodium butyrate in vitro and in vivo: a potential method for treating EBV-positive malignancies. Cancer Res. 2000; 60:5781-5788. [PubMed: 11059774]

18. Ghosh SK, Perrine SP, Williams RM, et al. Histone deacetylase inhibitors are potent inducers of gene expression in latent EBV and sensitize lymphoma cells to nucleoside antiviral agents. Blood. 2012; 119:1008-1017. [PubMed: 22160379]

19. Miller G, El-Guindy A, Countryman J, et al. Lytic cycle switches of oncogenic human gammaherpesviruses. Adv Cancer Res. 2007; 97:81-109. [PubMed: 17419942] 
20. Wen W, Iwakiri D, Yamamoto K, et al. Epstein-Barr virus BZLF1 gene, a switch from latency to lytic infection, is expressed as an immediate-early gene after primary infection of B lymphocytes. J Virol. 2007; 81:1037-1042. [PubMed: 17079287]

21. Tang W, Harmon P, Gulley ML, et al. Viral response to chemotherapy in endemic burkitt lymphoma. Clin Cancer Res. 2010; 16:2055-2064. [PubMed: 20233888]

22. Datta AK, Colby BM, Shaw JE, et al. Acyclovir inhibition of Epstein-Barr virus replication. Proc Natl Acad Sci U S A. 1980; 77:5163-5166. [PubMed: 6254061]

23. Balfour HH Jr, Hokanson KM, Schacherer RM, et al. A virologic pilot study of valacyclovir in infectious mononucleosis. J Clin Virol. 2007; 39:16-21. [PubMed: 17369082]

24. DiNardo CD, Tsai DE. Treatment advances in posttransplant lymphoproliferative disease. Curr Opin Hematol. 2010; 17:368-374. [PubMed: 20473161]

25. Perrine SP, Hermine O, Small T, et al. A phase $1 / 2$ trial of arginine butyrate and ganciclovir in patients with Epstein-Barr virus-associated lymphoid malignancies. Blood. 2007; 109:2571-2578. [PubMed: 17119113]

26. Magrath IT. African Burkitt's lymphoma. History, biology, clinical features, and treatment. Am J Pediatr Hematol Oncol. 1991; 13:222-246. [PubMed: 2069232]

27. patte C, Auperin A, Michon J, et al. The Societe Francaise d'Oncologie Pédiatrique LMB89 protocol: highly effective multiagent chemotherapy tailored to the tumor burden and initial response in 561 unselected children with B-cell lymphomas and L3 leukemia. Blood. 2001; 97:3370-3379. [PubMed: 11369626]

28. Hesseling P, Broadhead R, Mansvelt E, et al. The 2000 Burkitt lymphoma trial in Malawi. Pediatr Blood Cancer. 2005; 44:245-250. [PubMed: 15547922]

29. Funch DP, Walker AM, Schneider G, et al. Ganciclovir and acyclovir reduce the risk of posttransplant lymphoproliferative disorder in renal transplant recipients. Am J Transplant. 2005; 5:2894-2900. [PubMed: 16303002]

30. American Society of Hospital Pharmacists. AHFS Drug Information, 1989. Bethesda, MD: Board of Directors of the American Society of Hospital Pharmacists; 1989. p. vPublished by authority of the

31. Marshall BC, Koch WC. Antivirals for cytomegalovirus infection in neonates and infants: focus on pharmacokinetics, formulations, dosing, and adverse events. Paediatr Drugs. 2009; 11:309-321. [PubMed: 19725597]

32. Burns LJ, Miller W, Kandaswamy C, et al. Randomized clinical trial of ganciclovir vs acyclovir for prevention of cytomegalovirus antigenemia after allogeneic transplantation. Bone Marrow Transplant. 2002; 30:945-951. [PubMed: 12476289]

33. Simon MW, Fish DN, Deeter RG. Pharmacokinetics and safety of valaciclovir in children with Epstein-Barr virus illness. Drugs R D. 2002; 3:365-373. [PubMed: 12516939]

34. Nadal D, Leverger G, Sokal EM, et al. An investigation of the steady-state pharmacokinetics of oral valacyclovir in immunocompromised children. J Infect Dis. 2002; 186(suppl 1):S123-S130. [PubMed: 12353197]

35. Lansky SB, List MA, Lansky LL, et al. The measurement of performance in childhood cancer patients. Cancer. 1987; 60:1651-1656. [PubMed: 3621134]

36. National Cancer Institute. Common Terminology Criteria For Adverse Events (CTCAE). Bethesda, MD: US Dept. of Health and Human Services, National Institutes of Health, National Cancer Institute; 2009. Rev. ed.

37. Ryan JL, Fan H, Glaser SL, et al. Epstein-Barr virus quantitation by real-time PCR targeting multiple gene segments: a novel approach to screen for the virus in paraffin-embedded tissue and plasma. J Mol Diagn. 2004; 6:378-385. [PubMed: 15507678]

38. United States Pharmacopeial Convention. The United States pharmacopeia, 1979. Version 2007. Rockville, MD: United States Pharmacopeial Convention, Inc; Committee of Revision.

39. Calis JC, Phiri KS, Faragher EB, et al. Severe anemia in Malawian children. N Engl J Med. 2008; 358:888-899. [PubMed: 18305266]

40. To EW, Chan KC, Leung SF, et al. Rapid clearance of plasma Epstein-Barr virus DNA after surgical treatment of nasopharyngeal carcinoma. Clin Cancer Res. 2003; 9:3254-3259. [PubMed: 12960110] 
41. Lo YM, Leung SF, Chan LY, et al. Kinetics of plasma Epstein-Barr virus DNA during radiation therapy for nasopharyngeal carcinoma. Cancer Res. 2000; 60:2351-2355. [PubMed: 10811107]

42. Bornkamm GW. Epstein-Barr virus and the pathogenesis of Burkitt's lymphoma: more questions than answers. Int J Cancer. 2009; 124:1745-1755. [PubMed: 19165855]

43. Nerurkar AY, Vijayan P, Srinivas V, et al. Discrepancies in Epstein-Barr virus association at presentation and relapse of classical Hodgkin's disease: impact on pathogenesis. Ann Oncol. 2000; 11:475-478. [PubMed: 10847469]

44. Chan AT, Ma BB, Lo YM, et al. Phase II study of neoadjuvant carboplatin and paclitaxel followed by radiotherapy and concurrent cisplatin in patients with locoregionally advanced nasopharyngeal carcinoma: therapeutic monitoring with plasma Epstein-Barr virus DNA. J Clin Oncol. 2004; 22:3053-3060. [PubMed: 15284255]

45. Lin JC, Wang WY, Chen KY, et al. Quantification of plasma Epstein-Barr virus DNA in patients with advanced nasopharyngeal carcinoma. N Engl J Med. 2004; 350:2461-2470. [PubMed: 15190138]

46. Fan H, Nicholls J, Chua D, et al. Laboratory markers of tumor burden in nasopharyngeal carcinoma: a comparison of viral load and serologic tests for Epstein-Barr virus. Int J Cancer. 2004; 112:1036-1041. [PubMed: 15386346]

47. Lo YM, Chan LY, Chan AT, et al. Quantitative and temporal correlation between circulating cellfree Epstein-Barr virus DNA and tumor recurrence in nasopharyngeal carcinoma. Cancer Res. 1999; 59:5452-5455. [PubMed: 10554016]

48. Sala A, Pencharz P, Barr RD. Children, cancer, and nutrition-a dynamic triangle in review. Cancer. 2004; 100:677-687. [PubMed: 14770421]

49. Israëls T, Chirambo C, Caron HN, et al. Nutritional status at admission of children with cancer in Malawi. Pediatr Blood Cancer. 2008; 51:626-628. [PubMed: 18668514]

50. Bauer J, Jürgens H, Frühwald MC. Important aspects of nutrition in children with cancer. Adv Nutr. 2011; 2:67-77. [PubMed: 22332035]

51. Israëls T, van de Wetering MD, Hesseling P, et al. Malnutrition and neutropenia in children treated for Burkitt lymphoma in Malawi. Pediatr Blood Cancer. 2009; 53:47-52. [PubMed: 19338050] 


\section{Clinical Practice Points}

- There is interest in using nucleoside analogs against several Epstein-Barr virus (EBV)-associated diseases including endemic Burkitt's lymphoma (BL).

- Safety of nucleoside analogs in combination with chemotherapy in the developing world has not been studied.

- We conducted a phase $13+3$ dose-escalation trial and found that the combination of valacyclovir ( $15 \mathrm{mg} / \mathrm{kg}$ and $30 \mathrm{mg} / \mathrm{kg}$, 3 times daily for 40 days) and cyclophosphamide (40 mg/kg day $1,60 \mathrm{mg} / \mathrm{kg}$ on days 8,18 , and 28$)$ was safe and did not lead to any dose-limiting toxicity.

- The most common side effects observed were vomiting, abdominal pain, and tumor site pain.

- We recommend a phase 2 valacyclovir dose of $30 \mathrm{mg} / \mathrm{kg} 3$ times daily for 40 days.

- We also observed that 6 of 12 patients with presumed BL had measurable EBV viral loads that decreased over the course of their treatment, suggesting phase II studies should investigate this correlation further. 


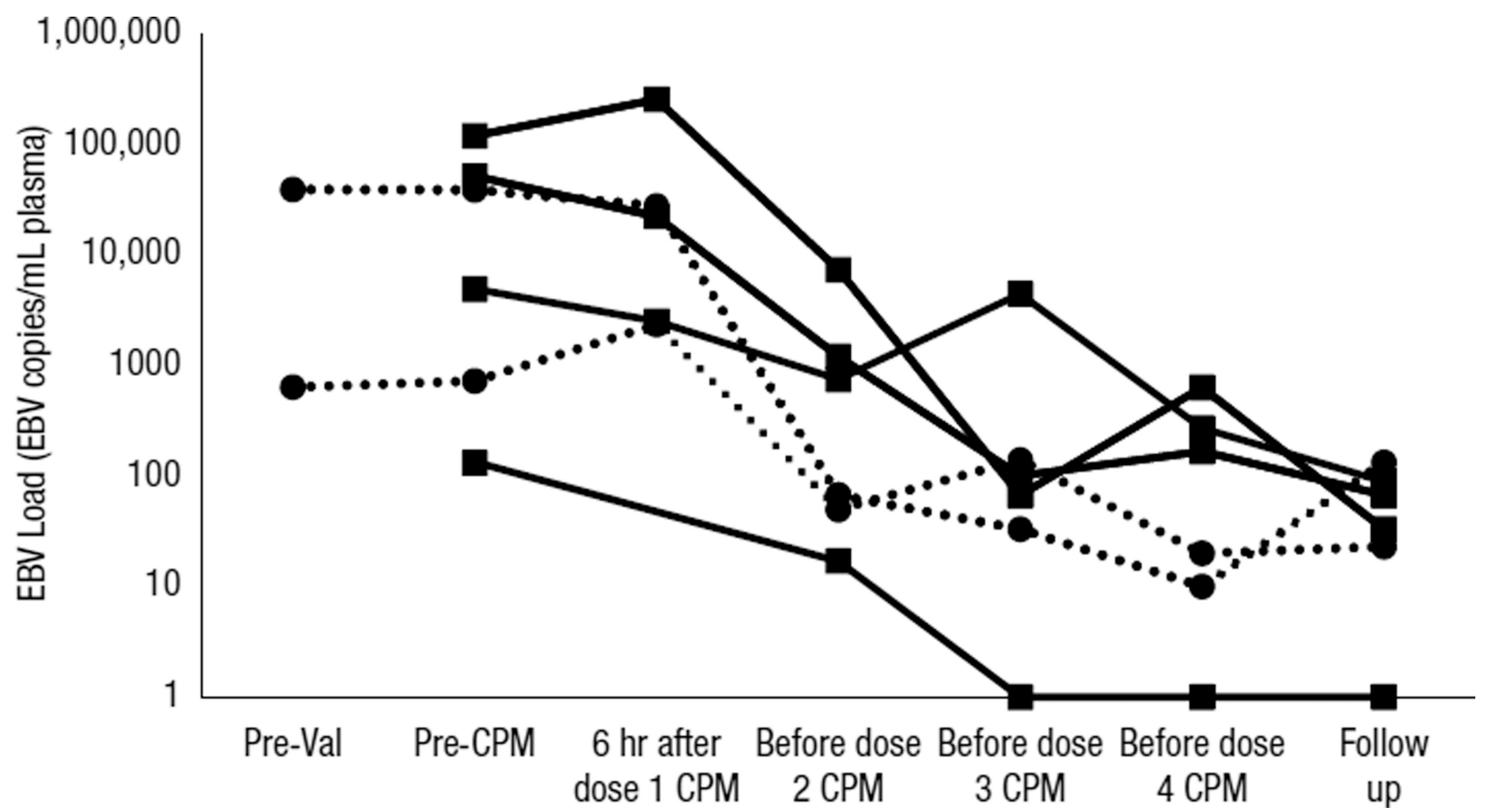

Figure 1.

Epstein-Barr Virus (EBV) Viral Load by Subject Number and Study Arm in Serial Plasma Specimens. Dotted Lines Represents Valacyclovir-Cyclophosphamide Regimen, Solid Lines Represent Cyclophosphamide Only

Abbreviations: $\mathrm{Val}=$ valacyclovir; $\mathrm{CPM}=$ cyclophosphamide . 
Table 1

Baseline Characteristics of Enrolled Patients

\begin{tabular}{l|c|c|c}
\hline Variable & $\begin{array}{c}\text { Control Group } \\
(\mathbf{n}=\mathbf{6})\end{array}$ & $\begin{array}{c}\text { Valacyclovir Group } \\
\mathbf{1 5} \mathbf{~ m g / k g}(\mathbf{n}=\mathbf{3})\end{array}$ & $\begin{array}{c}\text { Valacyclovir Group } \\
\mathbf{3 0 ~} \mathbf{~} \mathbf{f} / \mathbf{k g}(\mathbf{n}=\mathbf{3})\end{array}$ \\
\hline Male Sex (\%) & $2(33 \%)$ & $1(33 \%)$ & $2(67 \%)$ \\
\hline Age, $\mathbf{y}$ (Median, Range) & $7.5(5-13)$ & $10(7-15)$ & $6(3-9)$ \\
\hline Height/Age $z$-Score (Median) & -3.28 & -1.99 & 0.48 \\
\hline Duration of Facial Mass, d (Median, Range) & $40.5(20-90)$ & $28(21-30)$ & $51(7-51)$ \\
\hline Facial Tumor Largest Diameter, cm (Median, Range) & $5(2.5-8)$ & $9(7-12)$ & $7.5(6-13)$ \\
\hline Abdominal Mass Present, $\mathbf{n}(\%)$ & $3(50 \%)$ & $2(67 \%)$ & $2(67 \%)$ \\
\hline
\end{tabular}




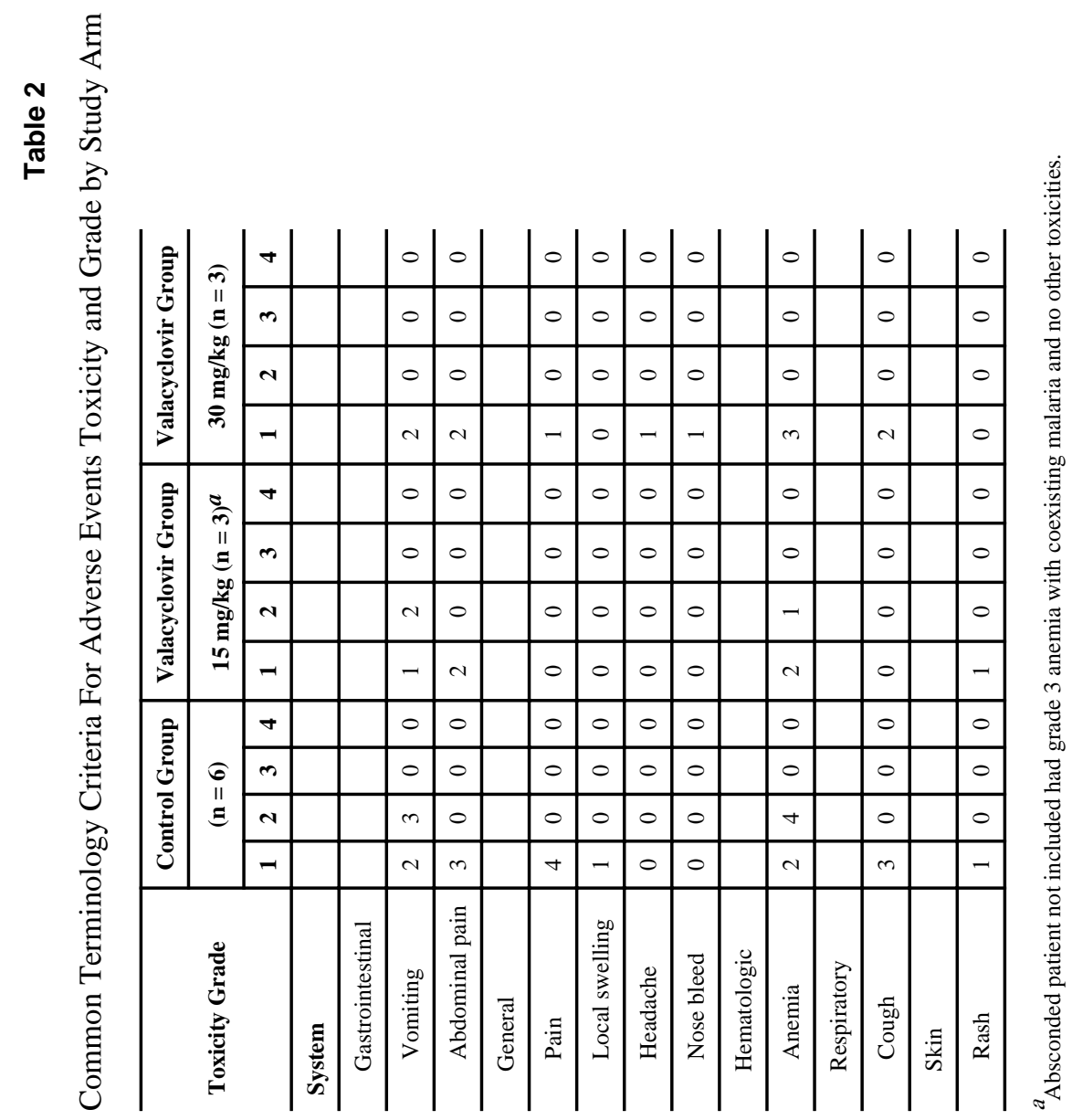

Clin Lymphoma Myeloma Leuk. Author manuscript; available in PMC 2014 April 01. 